\title{
The Ironic Conditions of Clinics and Schools
}

\begin{abstract}
We can't expect people to run towards care when the care isn't good. PAUL FARMER, "FAILURE TO COLLIDE: EBOLA AND MODERN MEDICINE," 2015
\end{abstract}

One sunny afternoon in Sonsonate, I was approached by a Juntos mother named Paloma. She was the first person I had met in the village, and we had developed a close relationship. I often started and finished my days chatting with her and a variable combination of her seven children in the small courtyard of her humble home. Looking much more serious than usual, Paloma asked if I would volunteer to teach English at the secondary school her children attended and that she had once attended herself. She explained that it would be a temporary arrangement, just until the school director filled the vacant position. After chatting it over with her, I agreed, and Paloma promptly whisked me over to seek consensus from two fathers in the parents' association, who were busy with shovels making improvements to one of the school buildings. ${ }^{1}$ The men's nods of approval secured, Paloma led me to the director's office. After a brief meeting in which the director implored me to make a monetary donation, which I politely explained I could not provide, I was introduced to the other teachers and provided with my schedule. I was to start the next day. ${ }^{2}$

The Sonsonate secondary school was built through the unpaid labor of community members, who identify that effort an act of mit'a, voluntary public service, with great pride. But community members were unable to supply the school with some important equipment that the state had neglected to provide. The toilets were not serviced with running water, and there was nowhere in the school to wash one's hands. The school had a small, locked room in which staff stored boxes of outdated textbooks, but there was no library at the school, or anywhere else in the village, where students could find books on subjects of general interest. Moreover, the reading materials available didn't reflect the realities of rural 
livelihoods or the contributions of rural people. The English textbooks were clearly written for an urban student body; the vocabulary provided for students to use when answering the question "What do your parents do?" included pilot, doctor, and accountant, professions that none of the students' parents-subsistence farmers, construction workers, or migrant laborers, held. It was about as disconnected as the textbook's section on technology; I never encountered a single student at the school who owned a computer, and the one in the director's office was not available for student use.

My three weeks spent teaching at the school helped me better understand the context in which Juntos mothers met program conditions, as did my observations of and conversations with women in clinics and day-care centers, municipal halls, and community centers, and in households and on terrenos (plots of land). Mothers like Paloma had a different view of conditionality than the experts based in Lima. These mothers' experiences provide key insights into questions that much of the quantitative research on CCTs overlooks: Why do poor, rural people need a "nudge" to attend health and education services? And when the cash incentive does drive the intended behavioral changes, what do poor women and their children encounter at health and education services?

\section{TEACHER SHORTAGE}

Before being approached by Paloma, I had wondered why the schoolyard was so often occupied with seemingly idle children during regular hours of instruction. As it turned out, over a period of more than two months, an ongoing "teacher shortage" (falta de profesores) meant that over half the secondary students in Sonsonate, Santa Ana District, missed classes in English, communications, and biology. The reason cited by the school's director was that "there was no budget." During my stint as a substitute teacher, I observed that depending on the grade, students could spend up to three hours out of a five-hour school day without classes. Their mothers, nearly all of whom were Juntos recipients, ensured that they arrived promptly at school in order for them to pass hours in the courtyard patch of gravel and brush, chatting or kicking around a deflated soccer ball.

The issue of idle children and inadequate staffing that I encountered at the school in Sonsonate was not limited to this one school. The regional capital city, Cajamarca city, also suffered a teacher shortage, and this too was identified by education staff and frustrated parents alike as a budgetary issue. Around this time, the local newspaper reported that the regional government had petitioned the Ministry of Education for 24 million soles (at the time US\$9,184,878) in order to contract with enough teachers to fill the vacant spots (El Panorama 2013). According to mothers whose children attended the secondary school in Sonsonate (which also served a number of surrounding villages), the teacher shortage was 
an annual occurrence. Teacher shortages, however, were only one of a number of reasons for which the quality of education in rural Peru was commonly characterized as pésima, or "terrible."

Absenteeism-teachers simply not reporting to work-was another persistent issue in Cajamarca and elsewhere in the country. A survey conducted by researchers at Harvard University, the World Bank, and the Peruvian think tank Grupo de Análisis para el Desarrollo tracked teacher absenteeism at primary schools in Peru. Their findings included a strong connection between geography and absenteeism. According to the study, "Teachers at public schools in higherpoverty districts are absent twice as often as other public school teachers, and for teachers at remote public schools (measured by distance to a paved road), absence rates are two and a half times those of other public school teachers" (Alcázar et al. 2017, 124). ${ }^{3}$ Reasons for absenteeism included remoteness (rural communities are hard to reach and involve extended absences from family); underresourced classes and unpleasant working conditions; poor salary; and weak community ties, or limited sentiments of accountability toward the local community (Alcázar et al. 2017). In wealthier countries, an absent teacher is likely to be replaced by a substitute. This was not the case in rural Peru. "In a developing-country setting, where substitute teachers are uncommon, absence of a primary-school teacher may have various consequences-doubling up of classes, idle time for students, and even student dropouts if absence becomes frequent enough. But learning is not likely to be one of them" (Alcázar et al. 2017). Notably, Juntos mothers were required to send their children to school, regardless of whether the teacher showed up for work.

Even when the schools were fully staffed, Juntos mothers raised the issue of poor-quality instruction. The students in my classes were enthusiastic, volunteering answers and requesting extracurricular classes. However, even in the upperlevel classes, students' level of language acquisition was strikingly poor. This was not through any apparent fault of their own. The students reported that their previous teacher, who had gone on to teach other subjects, did not know how to speak English-a point I was later able to confirm with that teacher. At the time of my research, local and national newspapers frequently reported on the exceedingly low number of teachers able to pass the qualifying professional exam. For instance, in a rural region that neighbored Cajamarca, of 2,125 teachers who stood for the qualifying English exam only 25 of these passed. The local Ministry of Education representative responded with a disheartening dose of pragmatism: “The results are alarming, only 25 passed the exam, but what are we going to do? We have to fill 500 spots" (La Republica 2013).

Placing blame on teachers for poor-quality instruction would be misguided. Public school teachers in places like Santa Ana operate in an underfunded system that does not adequately invest in training and resources, particularly in rural areas. In The Education Trap in Peru: When Education Reaches Many and Serves 
Few, researchers Arlette Beltrán and Janice Seinfeld (2013) of the Universidad del Pacífico in Lima underscored the inadequacy of teacher training and poor salaries attached to the profession as central drivers of persistently poor educational outputs. Provocatively, they suggested that the only solution to the persistent problem of poor education was to remove all of the unqualified educators; any teacher or director who could not pass a pedagogical evaluation could be reassigned to an administrative position. They also implored the state to ensure that schools meet minimum infrastructural standards, supplying water, lights, an Internet connection, a library, whiteboards, and a guaranteed six hours of instruction daily.

In Cajamarca it was immediately apparent how the failures of the state affected children. The results of a national standardized test provided to second grade students in public and private schools revealed that only 30.9 percent of students in the country registered at a satisfactory literacy level, meaning that they understood what they had read (MINEDU 2013). In Cajamarca, only 19 percent of students registered at a satisfactory level of literacy. ${ }^{4}$ When those same students were tested in math, 12.8 percent of students nationally and 9.5 percent of students in Cajamarca were able to resolve numeric problems indicating an adequate level of skill, such as: "There are 26 pencils in a box. 14 are red and the rest are blue. How many pencils are blue?" Nationally, almost half of all students were unable to identify simple numeric relations, like which number in a scrambled sequence was the largest $(3,8,6$, or 5 ?), indicating the most basic grasp of math. In Cajamarca, this percentage was 57.7. Some regions faired even worse than Cajamarca; of all the regions tested, Cajamarca ranked twentieth out of twenty-six in reading comprehension and fifteenth out of twenty-six in mathematics. The results indicated a significant geographical gap: urban and coastal areas registered higher scores than the rural Andean sierra and Amazon regions-places where the state uses Juntos to ensure that parents send their children to school.

To be sure, the Peruvian government has undertaken a number of efforts to improve the state of education over the past decade and a half. The administrations preceding Humala invested in the construction of new schools and, through initiatives like Juntos, reduced the rate of student desertion and the number of students receiving good-quality subsidized lunches. However, substantial improvements to educational output-other than attendance-have been largely elusive. Following an extended period of news media coverage of the teacher shortage, the Ministry of Education announced the government was dedicating 446 million soles (US\$170,763,485) to improve school infrastructure in over two hundred schools located throughout the country (El Comercio 2013C). The ministry was also in the process of implementing reforms in order to improve the quality of instruction students received, including in rural areas. The extent to which these investments were successful remained to be seen.

Juntos mothers sent their children to school knowing that the quality of education they would receive there was poor. Most of the mothers I spoke with in 
Cajamarca were largely unaware of the discussion about education taking place on the national level; they were, however, exceptionally keyed in to what was happening locally. Juntos recipient Paloma spoke to me about the teacher shortage one afternoon as we walked back from her small plot of land. Paloma, who had a bundle of ears of white corn larger than her own body secured to her back, told me that before Juntos, many families didn't send their children to school. Instead, the children helped their parents cultivate the land and raise animals, a common practice across Latin America's smallholder farms. Nowadays, she told me, women are obligated to send their children to school, and so everybody did it, "but there are no teachers!" Sharply identifying the irony of the situation, Paloma wittily quipped, "Perhaps it's the teachers' attendance that should be monitored." Other mothers echoed Paloma's sentiments.

In light of such evidence, we can hardly blame these women for asking, Who is really responsible for poor outcomes? When children become adults who are unequipped to take advantage of economic opportunities (to borrow language from development experts), who should take responsibility?

These women's perspectives challenge the very premise of conditionality and the supposed necessity of a "nudge" to ensure that households uphold their end of the bargain in sharing responsibility for overcoming poverty. Persistent staff shortages, low quality of instruction, and inadequate infrastructure are manifestations of the state's failure to redress persistent inequalities in the distribution of basic resources (Oliart 2003). While women upheld their end of the bargain by sending their children to school, the state failed to provide the infrastructure and human resources necessary to provide a quality education. Yet, notably, while women's compliance in meeting conditions was monitored, there was no simultaneous audit of the state.

In addition to their comments, women's actions, too, demonstrated a great deal of responsibility for the education of their children. Aside from securing a substitute teacher (at no cost to the school), Paloma and other mothers and fathers from Sonsonate decided to forgo their subsistence tasks and traveled to Cajamarca city to protest the teacher shortage outside the Department of Education. Not long after, the local newspaper reported on an organized group of parents protesting a sustained case of absenteeism on the part of teachers and the school director in a neighboring district (Cruzado 2013). My findings corroborated evidence from elsewhere in Peru that documented the significant efforts expended by rural parents to ensure their children received a meaningful education (Figueroa et al. 2010). Research among mothers in the Mexican CCT program registered similar concerns about teacher absenteeism; there, mothers astutely proposed a reduction in teachers' salaries to correspond with the fines women faced for not doing what was expected of them (Rivero 2002, cited in Molyneux 2006, 435). The point raised by mothers in Mexico and Peru troubles the assumption undergirding CCT policy, 
that poverty is a result of poor people's irresponsibility. Paloma was but one of the many mothers I met who assumed the responsibility for improving their children's access to education, even when the state was apparently failing to do the same.

\section{DISCRIMINATION IN SERVICE ACCESS}

When CCTs successfully increase children's uptake of health and education services, they also expand women's interactions with public services. It is well established that women's exposure to public spaces and actors can lead to increased self-esteem and empowerment, at least at the local level. While women's wellbeing or empowerment was not an aim of Juntos, it is worth exploring the nature of experiences CCT recipients have when they use public services. To be sure, I observed indicators of empowerment that have been more intentionally explored by a handful of studies in Peru and elsewhere, including increased purchasing power within their communities and a more positive outlook on life, especially as it related to their capacity to provide for their children (Alcázar et al. 2016; Correa Aste and Roopnaraine 2014; Latapí and la Rocha 2008). ${ }^{5}$ My observations indicated that some Juntos mothers interacted confidently with public services and, in particular, with the education system. Paloma was an exemplary case of this: she participated in the parents' association, protested the teacher shortage, and successfully inserted me into a teaching position at the local school. ${ }^{6}$

Yet it was unclear to me, and the jury remains out-in the broader albeit limited research on women's empowerment and CCTs-on whether Juntos was a catalyst of this participation. A number of women like Paloma arrived at their interactions with public service providers as already relatively empowered individuals. In her case, Paloma had experience as a community leader in other social programs, took advantage of local trainings and microproductive projects, owned a small plot of land in her own name, and had a husband widely recognized in the community for treating her well. Not all mothers came to Juntos with these same experiences.

But even mothers like Paloma were not immune from features of the public services system that were grounded in prejudice. For campesinas, discrimination at the hands of public service providers is a regrettably common experience. ${ }^{7}$ Such experiences include being ignored, made to wait, and being addressed disrespectfully. For example, Juntos mother Grimalda was very well respected by other mothers in the village. She was always smiling and her three children were cheerful and affectionate with their parents. Like all the other Juntos mothers I spoke with in Sonsonate, Grimalda disliked the director of the secondary school, a mustached man from the city who distinguished himself from the school's rural families on the premise of being "a good Christian." Mothers frequently commented that "the director doesn't do his job," and my own observations supported their claims. During the three-week period when I taught at the school, I bore witness 
to several occasions in which the director was absent from work, sometimes even leaving teachers and students locked out of the school.

Mundane abuses of power were commonplace. Mothers reported that the director corruptly charged them a fee for access to their children's enrollment and graduation certificates, which Juntos required the women to provide. When the mothers protested, the director laughed at them, and so the women paid the fees. If they refused, the mothers risked suspension from the Juntos program on account of failure to prove compliance with program conditions. On multiple occasions I saw mothers made to wait while the director sorted through paperwork on his computer, the only one in the school (and to my knowledge, the surrounding villages). On one illustrative occasion, Blanca, a slight, quiet woman in the full, calf-length dark skirt and white blouse typical of campesina dress, approached the doorway of the director's office and, without entering, asked politely if someone would please unlock the gate so that she could leave. Without making eye contact, the director snapped, "I have other things to do!" Blanca was also ignored by his young female secretary, who never looked up from her desk. After waiting a moment, Blanca retreated to wait silently by the locked gate. ${ }^{8}$

Commonplace acts of interpersonal discrimination and unsanctioned feecharging were indicative of larger patterns of inequality. Social scientists Martiza Paredes and Rosemary Thorp situate the poor quality of present-day education services in rural Peru within the historical context of discriminatory patterns of public funding and social policy (Thorp and Paredes 2010; Paredes and Thorp 2015). In the early twentieth century the Peruvian state increased its nearnonexistent spending on education in the rural Andes in order to civilize and assimilate indigenous populations through a curriculum promoting literacy and personal hygiene. Prejudiced attitudes against indigenous and campesino people cut through educational policies and laid the foundation for grievous mistreatments. In some of the worst incidents, young women were humiliated and sexually abused by their teachers (Thorp and Paredes 2010). Despite increased investment in education, literacy rates in the region barely improved. This example illustrates how "poverty traps" work. Nothing was done to modify deeply ingrained discriminatory attitudes and beliefs about the inferiority of campesino and indigenous people; and as a result, "while the resources did get delivered the outcomes were perverted" (Paredes and Thorp 2015, 8).

This historical policy environment provides important context for contemporary attempts to "include" the poor and marginalized. Juntos required children to attend underresourced schools, generating perverse outcomes that included attending classes without teachers, using toilets without water, and finding libraries without books. For their mothers, the situation involved confronting discrimination and humiliation at the hands of school authorities. Poor women quite rightly pointed out the gross irony of this arrangement: Juntos effectively increased demand for services, without making those services any more desirable. 


\section{CONFRONTING HEALTH CARE}

Regarding health services, Juntos recipients confronted even worse conditions of access and quality. Some of the most salient issues came to the fore during a Juntos meeting in Labaconas. The meeting took place at ten oclock on a rainy morning in the municipal hall. It was attended by approximately forty Mother Leaders, elected village-level representatives of Juntos recipients who, among other things, served as liaisons between Juntos's local managers and the households in their jurisdictions. The two local managers responsible for Labaconas District had summoned the Mother Leaders from the surrounding hills to attend the meeting in the district capital. They arrived wearing wide-brimmed white sombreros and colorful shawls that they had likely knit themselves, and while chatting to one another they took seats in rows of plastic chairs. The local managers, easily identifiable in their fire-engine-red Juntos jackets, stood at the front of the hall. They were accompanied by the perpetually campaigning district governor and health staff from the surrounding clinics, including a newly appointed middle-aged male chief of staff, a young male technician, and a female nurse, all of whom wore the Western dress of urban dwellers.

When the meeting began, the local managers and health staff instructed the Juntos mothers to use health services when pregnant and on behalf of their children, which was framed as a matter of responsible behavior. In turn, the mothers queried the availability of services in their area. My field note from that day reads:

At half past ten the meeting starts, and the health chief begins by telling the quietly seated mothers not to come to the health post at night unless it is an emergency, not to ask for medicines, and not to show up expecting to be attended. Health staff, he says, will attend them from 7:30 a.m. to 7:30 p.m. He is aware that during the past six months women have been coming to the health post during open hours and not being attended; he assures them the municipality has contracted more staff to resolve the problem. A mother named Felisa addresses him from the rows of seated women, apologizing quietly and politely for the bother, and asks if they could possibly get a doctor at the health center in the district capital. The health chief replies that the health center has been downgraded from a "center" to a "post," so only provides primary care. Felisa says that just two weeks ago she was told at the center to take her very ill mother to Cajamarca [city] for treatment, at which point "they didn't even give me a pill." Felisa wasn't able to take her mother all the way to the city "because she didn't have the money" [por la economía]. The health chief responds that women should always have some money saved for emergencies. Solanda, to my left, says quietly to her neighbor: "And how do we do this?!” A woman with long plaits called Juana requests a turn to speak; in a firm tone but using all of the formalities, she says that she is from Lotan village, where there is often no one working at the health post (the staff from this post is also absent from the meeting). Juana asks what the mothers can do, can they come down to the district capital? And could they please have some health training to deal with issues themselves? She recounted that the other day a mother in her village gave birth alone because the nurse wasn't there. One of 
the other health staff interrupts to say that the nurse no longer works there, at which point Juana apologizes for the bother and takes her seat.

This meeting provided a view into rural women's experiences of accessing poorly distributed and resourced health care services, and the economic barriers mothers face in overcoming them. The landscapes in which Juntos was implemented were not like the urban spaces of Lima or even the city of Cajamarca. In rural Peru, women's access to care-for themselves and their families-was limited by the distances they had to travel in order to reach a health facility and by the lack of roads and public transportation. Despite the very obvious geographical and infrastructural barriers they faced, rural mothers encountered very little empathy from health staff; the health chief's response to Felisa's account of trying to access care for her ailing mother is a typical example.

For women like Felisa, who was poor enough to qualify for Juntos, this journey would be a time-intensive and costly affair. An average journey from where Felisa lived would entail three or more hours on foot from her village to the district capital, payment for travel by combi (which could include transferring to a different vehicle partway through the trip) or shared taxi depending on availability, and resulting in a journey of one and a half to two and a half hours to reach Cajamarca city, followed by the cost of an inner-city combi or taxi travel to the hospital. Felisa was responsible for the care of young children and would most likely have to bring them along. This would multiply transit, food, and lodging expenses. Once at the hospital, Felisa's family would likely queue for hours to be attended. Low- and noincome people, including Juntos recipients, were forced to queue out front starting at three oclock in the morning for a chance to be attended. The Cajamarca public hospital was staffed for outpatient care only in the mornings; in the afternoon, the doctors attended to higher-income patients at the modern, more expensive private hospital on the other side of the city. Given the prolonged amount of time required to seek treatment, the family would likely need lodging for the night (or more, depending on whether internment was required) and would have to eat in restaurants, which were expensive.

The health chief implied that Juntos recipients ought to be able to generate savings for use in unforeseen circumstances such as those Felisa confronted, yet mothers' accounts suggested that in most cases this was an unreasonable expectation. Mothers frequently referred to the cash payment Juntos provided as "a little bit of help" (ayudita). In addition to covering unforeseen costs with it, mothers spent the cash on a variety of things requested of them by local managers, teachers, and health staff, including photocopies, school supplies, enrollment and graduation certificates, uniforms, medication, meat, and fruit, as well as travel to places where they could purchase these things. Suniva, a mother of three school-age children and a Juntos recipient of five years, voiced a contention I heard often: "Two hundred soles are a little bit of help. People think you can live off of this, but you 
cannot." While women said that they were thankful for the money, a little bit of help was indeed little. All told, two hundred soles ran out quickly.

To access this bit of help, women were required to meet the seemingly straightforward health conditions imposed by Juntos: pregnant women were to attend prenatal appointments, and mothers had to bring children under the age of five to regular health checkups. The state of health care in rural Peru complicated women's capacity to accomplish these tasks efficiently. Clinics were frequently closed during regular hours of operation, a reality I found evidence of in my travels with local managers, in conversations with mothers, and in regular reports in the local and national newspapers. Closures were the result of staff absenteeism and high turnover, both of which are chronic problems in the rural countryside. In a World Bank-commissioned study on education and health-professional absenteeism in Peru, researchers visited approximately one hundred schools and one hundred clinics on two separate occasions. In 81 percent of the schools they visited, teachers were present on both occasions. Health staff were present for both visits in only 56 percent of facilities, one-third of staff were present on one visit, and a full 10 percent were absent on both occasions (Chaudhury et al. 2006). Low wages and difficult working conditions were oft-cited reasons for why health staff disappeared from the job, particularly in remote communities. Current and former health staff spoke to me about missing their families and not being equipped with the medical supplies necessary to do a good job. Local newspapers reported on chronically short-staffed clinics throughout the region, where technicians and nurses refused to travel tiresome distances for such low-paid work.

The consequences of absenteeism were particularly acute in rural areas because the absence of one or two health staff could result in the clinic being entirely closed for service. Juntos mothers were eligible to receive the cash incentive only when their attendance at appointments was recorded by health staff and registered by local managers. If a mother descended from the hills with her children to attend an appointment and found the clinic closed, she was required to make the journey again (figure 5). In order to comply with program conditions, women could be forced to travel for hours on foot to a health clinic several times just to check the box for a single prenatal exam or child's checkup.

My observations corroborated findings from research elsewhere in the country underscoring the gross waste of women's time generated by poor-quality health services (Ewig 2010, 142). To be sure, wasting time in this way might not be so problematic if Juntos mothers had time to spare. Since most Juntos recipients do not participate in the formal labor market, some observers might assume it is reasonable to ask unemployed women to make a few extra trips to a health clinic. In fact, women in the Andes spend on average fourteen to eighteen hours a day on productive and reproductive labor, do more agricultural work than men, and multitask, caring for children while spinning wool and pasturing animals (Deere 2005). Their contributions to family and community well-being in rural Peru are 


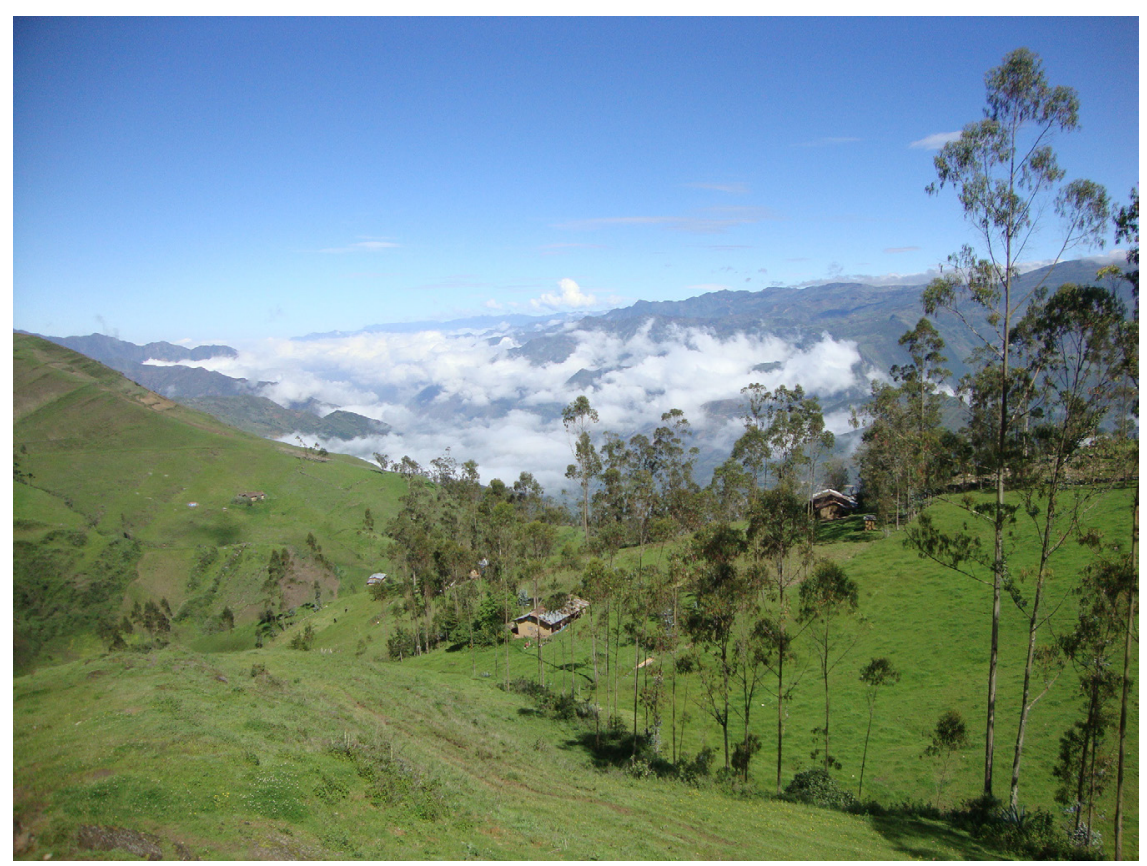

FIGURE 5. It was a three-hour walk to reach the health clinic in the valley below. Photo by the author.

extensive and significant, even if they are largely unpaid. Fulfilling the conditions Juntos imposed upon them constituted additional hours of labor. The time women wasted attempting to meet program conditions was time reallocated from subsistence agriculture, tending flocks, caring for sick and elderly dependents, helping children with schoolwork, or engaging in economically productive activities. These largely caring activities not only buffer families' experiences of acute poverty but also contribute to building and maintaining human capital-Juntos' explicit aim. The irony, and tragedy, of this situation was that CCTs were deployed to organize women's caring labor in a way that development experts-who do not share rural women's predicaments-deemed preferable to women's own arrangements.

\section{WHY DO WOMEN COMPLY?}

Given the poor quality of services and the personal cost of meeting the conditions that Juntos imposed, why did women comply? My observations and Juntos mothers' accounts indicated that women tried their best to fulfill the conditions because the cash had a positive material impact on household economies. It enabled them to meet some of the needs of their children and other dependents. Juntos recipient 
Santos, who cared for her young grandson, told me that Juntos was an important resource because local work was scarce: "if not for this little bit of help it would be very difficult. There's nowhere else to get [money] from. There is no work." Another Juntos recipient, Josepa, recounted how happy she was when the census takers finally arrived at her house, so that she could register for the CCT program: "As they say, it's a little bit of help, miss. Maybe to buy a little something . . . as there's no work. And, well, miss, if not, where do we [get money]?" Much like that of Santos, Josepa's appreciation of the cash payment-and fear of losing it-was grounded in her financial concerns as a single mother.

Reliable sources of income, however small, were valuable because there were few options for rural women otherwise. ${ }^{9}$ Cajamarca, like much of the rest of Andean Latin America, was subject to the "growing distress" of the peasant economy (Deere 2005). Women like Santos and Josepa operated in an economy that incentivized men to migrate out of the region in search of agricultural work. A consequence of this was a rise in female-headed households as temporarily or permanently abandoned women were left to juggle care work with access to paid labor, if there was any to be had. Juntos provided a consistent source of income that helped women to care for their families. Women welcomed a "little bit of help" when help was scarce.

To say that women appreciated the cash is not the same as suggesting that they complied with the conditions uncritically. Their compliance was not evidence of support, let alone enthusiasm. When women referred to the cash as a little bit of help they educated the listener on its limits. They were demonstrating awareness of the pejorative assumptions made about Juntos recipients by higher-income people with whom the mothers interacted in clinics and schools and the district capital, where they went to collect the payment. Paloma explained this dynamic in an interview:

I have the twins, plus Marcos and Juan, who are all studying. Four [children]. And one hundred soles for four children, well it doesn't cover everything [no alcanza]. Sure, it's a little help, but that's it. It doesn't cover everything. When we say, "Ok, let's go and queue so that they give us the hundred soles," the rest of the people say, "Look at those welfare recipients [pensionistas], how they're coming. They're doing really well getting a gift, the hundred soles." And they say, "Why [doesn't Juntos] give it to us, if we are the ones working?” That's what they say. ... We hear them say it.

In referring to the transfer as a little bit of help, mothers worked to dispel assumptions among non-Juntos recipients about the women's deservingness and the material conditions of their lives. As noted earlier, the cash transfer permitted mothers to purchase necessities, access services, and make modest investments that would otherwise be difficult or impossible, including basic medicines, school uniforms, extra protein, local transportation, and small livestock. The cash transfer did not, however, compensate for the lack of employment opportunities or level of government neglect in the rural countryside. 
Mothers' accounts and my observations also suggested that women complied with program conditions because using health and education services-even those of poor quality - was the responsible thing to do. Development and socialpolicy research examining the gendered design of CCTs in Mexico and Central America challenged the assumption that giving money to women was straightforwardly empowering by pointing out that CCT program design positioned mothers as responsible for their children's poverty (Molyneux 2006; Bradshaw and Víquez 2008; see also Chant 2008). Narratives about responsibility pervade the program from design to implementation. In Peru as well as other countries where CCTs are implemented, conditions are commonly referred to as "coresponsibilities," implying that the state and CCT recipients are jointly responsible for overcoming poverty. In the villages where Juntos was implemented, responsibility narratives circulated broadly. While women and even local managers regularly lamented the inadequacy of health and education services, these critiques were not explicitly framed in terms of the state's unmet "coresponsibilities."

In contrast, women's responsible or irresponsible behavior was frequently and explicitly in question. The choices of poor, rural women were often framed in terms of responsible and irresponsible motherhood by urban, middle-class experts in antipoverty programs, by doctors and nurses in health clinics, and by teachers and directors in schools. I frequently observed local managers imploring women to meet the program conditions as "responsible mothers," which they almost always did. These narratives have significant social power, functioning as they do to discipline women's behavior. Women themselves commented on their own or their neighbors' demonstration of responsibility as they cared for their children in the ways expected of them by the state.

To be clear, I am not suggesting that the mothers who participated in Juntos were so entirely constrained by the disciplining power of "responsible motherhood" that they acted without agency. To the contrary, decisions taken by women like Paloma, who fought to improve the conditions of her children's school, or made pointed comments made about the limits of "a little bit of help," stand as evidence of the ways in which Juntos recipients exercised agency. These were the most common ways that I observed women push back against a program that frequently made some aspects of their lives more difficult, even while it alleviated burdens elsewhere, and I am quite sure that there are others. ${ }^{10}$

What I am suggesting here is something quite different: that women's compliance with the burdensome and ironic demands of the state was informed by material constraints and disciplining social dynamics that ought to be taken seriously. Bear in mind the popular assumption by behavioral economists that poor mothers fail to use adequate services because they lack the motivation to do so. I am suggesting an alternative explanation: that poor mothers are already highly motivated and have their own reasons for complying. These alternative explanations for why women comply undercut the assumption that poor mothers simply need 
the motivation to access services that are otherwise perfectly adequate. In taking these alternative explanations seriously, it is possible to challenge the authority that compliance metrics grant to policy makers and program designers. Women's high rates of compliance do not prove that the quality of services provided by the state is adequate; all they prove is that desperately poor families do indeed need every little bit of help.

The chapter thus far has addressed two issues that the dominant body of evidence on CCT programs largely does not: what Juntos recipients encounter when they access education and health services on behalf of their children, and why, in the face of poor services, women decide to comply with program requirements. I return to the question of women's compliance in chapter 6 , where mothers' participation in a range of unsanctioned "shadow conditions" sheds light on the coercive power of cash incentives.

\section{CCTS OVERLOOK WOMEN'S HEALTH}

Who will provide care for the care provider?

AMMA DARKO

Juntos was concerned only with women's use of health services at a specific stage in their life course-when they were pregnant. Even then, program conditions were oriented toward the well-being of future children; nowhere did they focus on mothers themselves (Molyneux 2007). While Juntos mothers in Labaconas and Santa Ana dutifully whisked their children to growth and nutrition checkups, their own health needs remained unmet by the services available to them. Take, for instance, Yesenia, the Juntos mother of two whose experience opened this book. Yesenia had been diagnosed with breast cancer and was unable to access treatment anywhere within a ten-hour journey of the village where she lived. Her greatest concern revolved not around her own well-being but around who would care for her children if she were unable. By all accounts, she already was the sort of "responsible mother" that the state hoped to shape through use of behavioral incentives (Molyneux 2006; Bradshaw 2008). Yet when faced with a grave illness, she was presented with a host of economic and geographical barriers to care. The question of who provides care for care providers is not only practically relevantgiven that their labor sustains the well-being of others-it is also morally relevant. If we take seriously the contention that the inequitable distribution and insufficient recognition of care work are tightly linked to gender inequality, then care providers' access to care is also an issue of justice. ${ }^{11}$

Ninón, a frail and kindly Juntos mother, shared a number of Yesenia's motherly concerns. I interviewed Ninón outside of her home, perched in the sunshine on an earthy stoop. Ninón had been on bed rest for the better part of a year after a serious stomach operation. Abandoned by her husband many years previously, 
she was responsible not only for the care of two children but also for her elderly mother and her severely disabled brother. In places like rural Peru, where institutionalized care is sparse and expensive, poor women often assume responsibility for sick, disabled, and elderly family members who depend on them for survival. Ninón's ability to carry out this care work was compromised by her own ill health. As we chatted, she confided that she didn't attend all of the Juntos meetings, on account of her health, and was unsure whether Juntos would suspend her from the program. While local managers were not sanctioned to expel women on account of missing meetings, it bears noting that Juntos policy did not make exceptions for women who failed to meet health and education requirements because of illness. ${ }^{12}$ This raises the question of whether policy makers and program designers considered the significance of the work that women do, particularly as it extends beyond biological reproduction. What of their other care work and the good health necessary to accomplish it?

The lived realities of women like Yesenia and Ninón trouble the narrowly focused view of women's health embedded in CCT programs. Cases such as theirs illustrate that the targeted program design, which seems so sensible in theory, produces exclusionary and unjust ironies in practice. This is perhaps most striking when we consider the notion of coresponsibility. Certainly, a woman who cries because her cancer will affect her children, more than she cries for her own fate, stands as a rebuke to the view that poor people raise poor children because they are unmotivated.

\section{RESPONSIBILITY AND THE STATE}

Women's accounts of poor-quality services bring empirical backing to critiques other researchers have made about the capacity for CCTs to generate long-term positive impacts. While some of these critiques generate from quantitative studies of educational and health outcomes among children and youth (Murray et al. 2014; Cecchini and Soares 2015; Andersen et al. 2015), others look at social spending patterns (Lavinas 2013; Lavigne 2013). Social spending is what the state spends at its various levels of government to provide the public and private goods and services necessary to guarantee the social rights of the population; it does this through allocation of resources, redistribution of income, provision of preferential goods, and promotion of economic growth (Martínez and Collinao 2010, as cited in Lavigne 2013). Recall the high levels of absenteeism in clinics and schools, and the low salaries and difficult conditions cited by those skipping work: these are manifestations of inadequate social spending.

Development economist Lena Lavinas (2013) draws on comparative socialspending data across Latin America to show that while many CCT programs have increased the demand for health and education services, state governments have not met that demand with a proportionate investment in improving service supply: 
It is true that total social spending has risen sharply in Latin America. Between 1990-91 and 2008-09, according to ECLAC, average annual per capita expenditure went from $\$ 318$ to $\$ 819$, and the size of social spending as a share of GDP rose by 6.6 percent, accounting for 63 percent of all public expenditure in 2008-09, as against 45 percent in 1990-91. The trend certainly looks very positive. Nevertheless, this growth has been unbalanced: monetary benefits have registered greater increases than other modalities of public provision, such as spending on education, healthcare or housing. ... [M] onetary income transfers-either contributory, as in pensions, or means-tested benefits-accounted for over half the overall increase in public social spending, rising as a share of GDP by 3.5 percent between 1990-91 and 2008-09. By contrast, spending on health rose by only 1 percent over twenty years, and on housing by a mere 0.4 percent. (Lavinas 2013, 20, emphasis added)

Social spending in Peru is considerably lower than the Latin American average. In 2012, Peru spent 9.4 percent of GDP on social goods and services, compared to the regional average of 19.0 percent (ECLAC 2014). Since Juntos was created in 2006, overall social spending has increased. However, spending on health care and education have remained fairly steady. For instance, since 2006, expenditure on public health care as a percentage of GDP has fluctuated between 2.392 (in 2006) and 2.847 (in 2012). ${ }^{13}$ Yet during this period, Juntos dramatically increased the number of children regularly seeking health services (Perova and Vakis 2009). In this respect the aggregate social-spending data paint an even bleaker picture than my observations in rural Peru, suggesting not only that health care has not improved but also that it may be getting worse as rural care providers are increasingly overburdened. This data underscores a "flagrant contradiction in governments establishing CCT programs that require medical visits, when they have made little effort to provide better public healthcare" (Lavinas 2013, 21).

Only people situated at the bottom of the social hierarchy would be expected to contend with discrimination and subpar social services for a small (albeit not insignificant) cash stipend. It is important to recognize that this reflects a clear historical trend, in which the Peruvian state attempts to improve the life conditions of marginalized rural and indigenous populations without attending to broader political, social, and economic structures that perpetuate inequality. When the state fails to attend to unequal patterns of social spending and discriminatory beliefs, its interventions often prove ineffective and, in many cases, harmful (Paredes and Thorp 2015). While it would no doubt be politically unpalatable, there is good reason to think that the "intergenerational cycle of poverty" might truly be broken if the state were to address its grossly inequitable patterns of investment in the rural places where indigenous people live and the urban places where mostly nonindigenous elites live.

The 2016 World Social Science Report contends that tackling inequality requires a focus on how specific dimensions of inequality, whether gender, racial, spatial, political, cultural, or environmental, affect the life chances of particular groups. 
The report draws on data gathered globally to suggest that "the treatment of groups affects the well-being of individuals and their uptake of services that may help to reduce inequality, such as health and education. This means that reducing group-based inequalities can improve life chances for individuals, and increase the effectiveness of direct and indirect measures intended to address specific aspects of inequality" (ISSC et al. 2016, 8).

Unfortunately, "the institutional and cultural structures that sustain these [group] inequalities are often ignored and rarely addressed by the designers of change" (Paredes and Thorp 2015, 1). As it stands, the applause that governments receive for efficiently increasing service uptake masks what Lavinas stingingly called a "downsizing of social protection in the name of the poor" $(2013,40)$. In failing to meaningfully improve or perhaps even maintain the accessibility and quality of services available to rural families, Juntos compelled women and their children to confront the very markers of their poverty and exclusion. The everyday lives of Juntos mothers have much to tell us about how this contradiction plays out: in households, on footpaths, in clinics, and in schools. If the state ensured a reliable, good-quality, and culturally appropriate supply of health and education services, women and their families would almost certainly use them. What reason would they have not to? As it stands, the assumption driving CCTs-that poor people make irresponsible decisions and require incentives to make better onesis not based on adequate evidence, at least in rural Peru. Services there have never been good enough to test such an assumption.

\section{CONCLUSION}

Doctor and anthropologist Paul Farmer once said, "We can't expect people to run towards care when the care isn't good" (Farmer 2015). CCT programs, however, operate on the assumption that we can and should. The woefully ironic condition of clinics and schools begs the question of whether policy makers imagined that rural, indigenous populations were deserving of anything better than what was already on offer. In Peru and elsewhere, development experts impose conditions to ensure that poor people use health and education services on behalf of their children and to reassure the more powerful, tax-paying public that the poor are not being given a handout. Yet spending any substantial amount of time with rural mothers and their children reveals experiences that undercut the logic of conditionality. For instance: much like the middle-income and wealthy women in my own neighborhood, the poor mothers of rural Peru want to see their offspring thrive. A key difference in rural Peru is that women are afforded far fewer of the resources necessary to do so. In becoming defined by the anxieties, rigidities, and requirements of powerful groups and institutions, a well-intentioned policy of inclusion became a mechanism for delivering poor people to underfunded and ill-functioning clinics and schools. 
The poor condition of health and education services in rural Peru was widely conceded. The health chief in Labaconas acknowledged the six-month period in which the district clinics were understaffed, and farther up the chain of command in Lima, experts at Juntos and the Ministry of Development and Social Inclusion regretfully confirmed the inadequacy of rural services. Local managers tended to express the most empathy with women who had difficulty accessing health services, because these managers walked similar routes and frequently grappled with clinic closures when enforcing and monitoring conditionality. And yet, local managers continued to require women and their children meet the program conditions. At the end of the day, frontline Juntos staff were still responsible for implementing a successful program, and high rates of compliance enabled them to claim success.

Of course, the imperative to implement conditional programs of social support originates externally. State governments are encouraged to implement CCTs by authoritative external development agencies like the World Bank and the InterAmerican Development Bank (World Bank 2017; IDB 2009). To be sure, it is reasonable to suggest that these external agencies might not be aware of the poor quality of services in rural Peru. Yet there are plenty of data available. Take, for instance, the established global survey of the quality, equity, and efficiency of education systems carried out by the Organization for Economic Cooperation and Development's Programme for International Student Assessment. Peru consistently ranks near the bottom of the list; in 2015, it ranked sixty-fifth out of seventy countries (OECD 2016). Even lacking the kind of ethnographic data I've presented here, such surveys should give pause to the champions of CCTs. When ignorance of such readily available data results in requiring the rural and indigenous poor to use bad services, it is hardly an acceptable excuse.

This chapter has presented evidence of a significant lack of support for care work of the (poorly) paid and unpaid varieties. By looking behind high rates of program compliance, we see that the state neglected not only to account for the ways in which low-income, rural, campesinas labor to care for their families, but also to support them in that labor. Supporting them would require a critical look at the investments made in adequately remunerating teachers and medical staff, particularly in "last mile" communities. While the salaries afforded to teachers and medical staff were often not enough to entice them to work, the cash payment provided by Juntos effectively ensured that women and children arrived at clinics and schools. We know this is so because women's compliance with conditionality was monitored. But as this chapter has illustrated, compliance data does not tell the full story. 